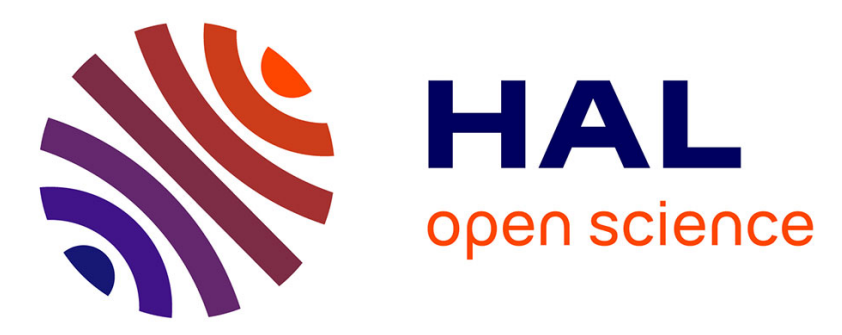

\title{
DCM-Operated Series-Resonant Inverter for the Supply of DBD Excimer Lamps
}

David Florez, Rafael Diez, Hubert Piquet

\section{To cite this version:}

David Florez, Rafael Diez, Hubert Piquet. DCM-Operated Series-Resonant Inverter for the Supply of DBD Excimer Lamps. IEEE Transactions on Industry Applications, 2014, 50 (1), pp.86-93. 10.1109/TIA.2013.2271216 . hal-01409259

\section{HAL Id: hal-01409259 \\ https://hal.science/hal-01409259}

Submitted on 5 Dec 2016

HAL is a multi-disciplinary open access archive for the deposit and dissemination of scientific research documents, whether they are published or not. The documents may come from teaching and research institutions in France or abroad, or from public or private research centers.
L'archive ouverte pluridisciplinaire HAL, est destinée au dépôt et à la diffusion de documents scientifiques de niveau recherche, publiés ou non, émanant des établissements d'enseignement et de recherche français ou étrangers, des laboratoires publics ou privés. 


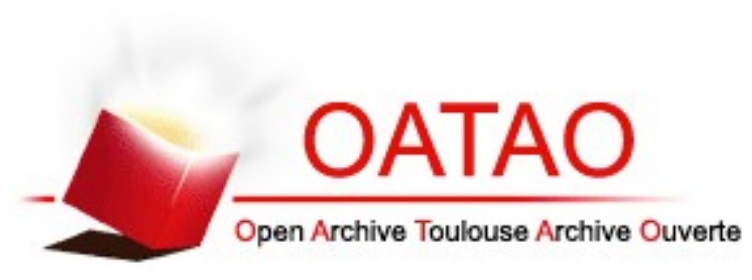

\section{Open Archive Toulouse Archive Ouverte (OATAO)}

OATAO is an open access repository that collects the work of Toulouse researchers and makes it freely available over the web where possible.

This is an author-deposited version published in: http://oatao.univ-toulouse.fr/ Eprints ID: 16690

To link to this article : DOI: 10.1109/TIA.2013.2271216

URL : http://dx.doi.org/10.1109/TIA.2013.2271216

To cite this version: Florez, David and Diez, Rafael and Piquet, Hubert DCMOperated Series-Resonant Inverter for the Supply of DBD Excimer Lamps. (2014) IEEE Transactions on Industry Applications, vol. 50 ( $\left.\mathrm{n}^{\circ} 1\right)$. pp. 86-93. ISSN 0093-9994

Any correspondence concerning this service should be sent to the repository administrator: staff-oatao@listes-diff.inp-toulouse.fr 


\title{
DCM-Operated Series-Resonant Inverter for the Supply of DBD Excimer Lamps
}

\author{
David Florez, Member, IEEE, Rafael Diez, Member, IEEE, and Hubert Piquet
}

\begin{abstract}
This paper presents the study of a series-resonant inverter for the supply of a dielectric barrier discharge excimer lamp. Causal analysis, based on the fundamental properties of the load, is used to detail the reasoning which has led to this topology. In order to effectively control the lamp power, the operating mode of this converter combines discontinuous current mode and soft commutation (zero-current switching), obtaining low electromagnetic emissions and reduced switching losses as well. The model of the lamp is briefly presented, and it allows a simple state plane analysis to calculate all the electric variables involved in the converter and, consequently, to select the components of the supply. The mathematical relationships obtained from this process, for injected power control by means of the available degrees of freedom, are validated with simulations and experimental results.
\end{abstract}

Index Terms-Dielectric barrier discharge (DBD), gas discharge devices, plasma sources, resonant inverter, ultraviolet (UV) sources, zero-current switching (ZCS).

\section{INTRODUCTION}

$\mathbf{T}$ HE DESIGN of an efficient power supply for a dielectric barrier discharge (DBD) excimer lamp, capable of controlling the ultraviolet (UV) emission, is a challenge because of the capacitive nature, the nonlinear behavior, and the high operating voltages of this load. In the past, different approaches have been proposed to supply different DBDs.

In the earliest experiments, sinusoidal voltage sources with frequencies from tens of hertz to tens of megahertz were used [1], followed by pulsed voltage sources [2], [3]. Lately, voltage-mode resonant converters for the supply of capacitive

D. Florez is with the Department of Electronics Engineering, Pontificia Universidad Javeriana, Bogotá, Columbia, and also with the Laboratoire Plasma et Conversion d'Energie (Unité Mixte de Recherche 5213), Centre National de la Recherche Scientifique-Institut National Polytechnique de ToulouseUniversité Paul Sabatier, Université de Toulouse, 31071 Toulouse, France (e-mail: d.florez@javeriana.edu.co; florez@laplace.univ-tlse.fr; david.florez@ laplace.univ-tlse.fr).

R. Diez is with the Department of Electronics Engineering, Pontificia Universidad Javeriana, Bogotá, Colombia (e-mail: rdiez@javeriana.edu.co).

H. Piquet is with the Laboratoire Plasma et Conversion d'Energie (Unité Mixte de Recherche 5213), Centre National de la Recherche ScientifiqueInstitut National Polytechnique de Toulouse-Université Paul Sabatier, Université de Toulouse, 31071 Toulouse Cedex 7, France (e-mail: hubert.piquet@ laplace.univ-tlse.fr). loads have been developed and implemented [4]-[6]. The main drawback of the voltage-mode approach in these converters is the inability to control and predict the power that is supplied to the discharge.

By studying the DBD lamp electrical model, it has been proved that the DBD electrical power can be controlled by means of its current instead of using its voltage; this is shown experimentally with a current-mode converter [7]. Additionally, the authors of [8] and [9] have clearly established a tight correlation between the current waveform and the temporal response of the UV radiation. In [10], a square-waveform current supply with three degrees of freedom has been designed to study the radiation of DBD lamps; however, this converter presents hard switching, diminishing efficiency and producing electromagnetic interference (EMI).

Among the possible topologies for the supply of DBD devices, resonant topologies offer less switching losses, less EMI, and a smaller number of switching devices than the others [11]. The voltage-mode resonant topologies proposed in [4] and [6] for DBD lamp and exhaust gas treatment, respectively, are, in our opinion, not the best choice to an efficient control of the operating point of DBD excilamps, as explained in Section II. In [7] and [12], current-mode resonant converters are developed specifically for excimer lamps. The topologies proposed in [5] and [13]-[18], based on the series-resonant inverter (SRI) or similar topologies, are adaptable to excimer lamp supplies. Using the classical SRI as basis and considering the DBD lamp electrical model, this paper presents an operating mode differing from the previous ones: It proposes the combination of the current-mode approach with the zero-current switching (ZCS). ZCS is achieved in all the switches at turn-on and turnoff, reducing EMI and increasing the overall efficiency.

This paper is organized as follows. Section II introduces the main aspects of the electrical model for a DBD excimer lamp. Section III explains the converter operating principle, using the lamp model. Section IV develops the mathematical relationships for the design of the converter, based on the state plane analysis. Section V dimensions the components for a specific $\mathrm{XeCl}$ excimer lamp and verifies the previous developments. Experimental results and conclusions are given in Sections VI and VII, respectively.

\section{DBD EXCIMER LAMP MODEL}

The modeling of DBD excilamps has already been presented in several papers, e.g., [19]-[21]; here, the most important elements are reminded: A coaxial DBD excimer lamp, as the 

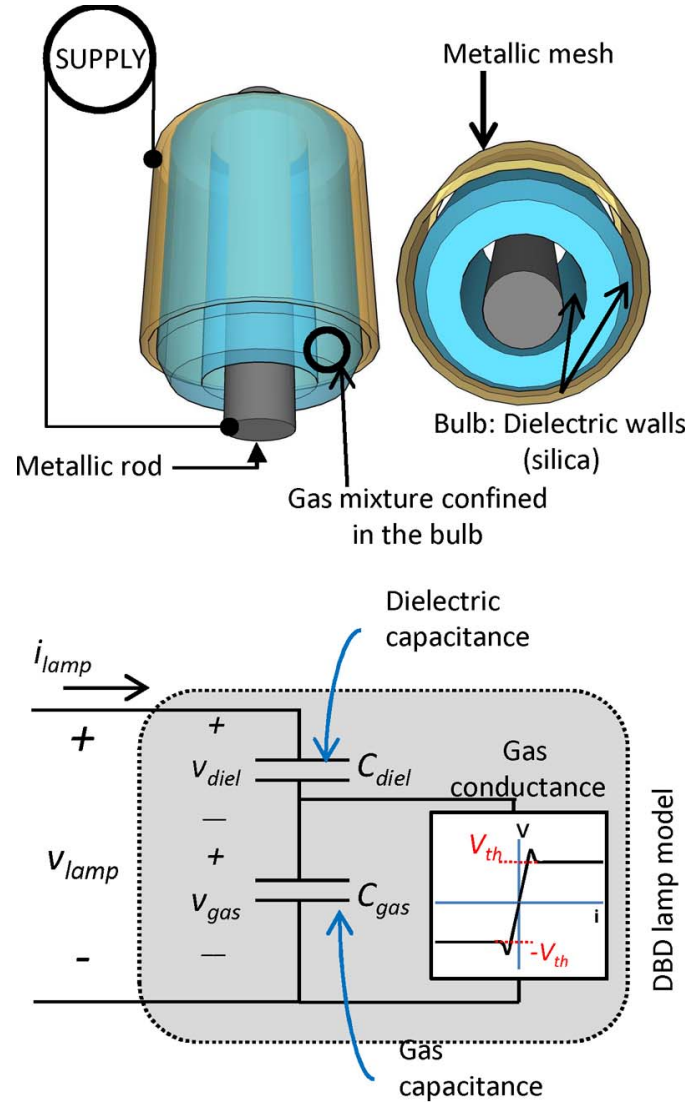

Fig. 1. (Top) Coaxial DBD excimer lamp and (bottom) its equivalent electrical model.

one depicted in Fig. 1, confines a gas mixture between two silica walls. This lamp geometry can be modeled with the electrical equivalent circuit in Fig. 1 (bottom). The lamp silica walls, acting as dielectric barriers, are modeled as the equivalent capacitance $C_{\text {diel }}$. These barriers are in series with the gas. The gas behavior is described by a gas capacitance in parallel with a gas conductance [21] ( $C_{\text {gas }}$ and $G_{\text {gas }}$, respectively). The gas conductance is very small when the absolute value of the gas voltage is smaller than the gas breakdown voltage $V_{\mathrm{th}}$ : The equivalent model of the DBD is thus the series association of $C_{\text {diel }}$ and $C_{\text {gas }}$. When the gas voltage reaches the breakdown voltage $V_{\mathrm{th}}$, by effect of the connected power supply, the gas acquires the behavior of an almost constant voltage source of value $V_{\mathrm{th}}$, which remains in series with $C_{\text {diel }}$. Experimental measurements and identification results [9] have proven that $V_{\mathrm{th}}$, which is a physical property of the gas, does not depend on the shape of the current waveform.

Taking into consideration the fact that, after breakdown, the gas presents an almost constant voltage, it is clear that the convenient supply mode to control the discharge power is to control the current which flows into the gas. From the lamp model, the current flowing through the gas conductance is equal to the lamp current (except for the time intervals, needed to install the breakdown conditions); in consequence, controlling the lamp current enables the control of the instantaneous power transferred to the gas [8].

Accounting its capacitive behavior, the supply mode of the lamp must enable a bidirectional current into the lamp (null average value); otherwise, the lamp voltage would grow uncontrollably, producing damage in the converter.

In the next section, we take advantage of the capacitive nature of the DBD to implement a resonant converter that uses the load as one of the elements of the resonant circuit.

\section{Discontinuous Resonant Supply Mode}

The classical topology of the SRI, shown in Fig. 2 (top left), presents a convenient current-source behavior [11], [15]. For this reason, this topology is chosen to implement the DBD current supply. In this topology, the inductance $L$ is connected in series with the DBD lamp through the full-bridge current inverter. The lamp current direction is determined by the bridge configuration.

The converter operating period is divided in six steps, determined by the bridge switches and the gas state. The equivalent circuit for each stage of this operating sequence is presented in Fig. 2 (bottom).

With the switches $S 1$ and $S 4$ turned on, an $L C$ seriesresonant circuit is obtained, as presented in Fig. 2(a), and the lamp current flows in the direction that will be defined as the positive one, henceforth.

Due to the resonance, the lamp current $i_{\text {lamp }}$ grows, as seen in Fig. 2 (top right), and consequently, the gas voltage $v_{\text {gas }}$ increases until it reaches the breakdown voltage $V_{\mathrm{th}}$. The breakdown occurs at time $t_{\mathrm{br}}$, and the gas is now represented by the constant voltage source $V_{\mathrm{th}}$, as shown in Fig. 2(b); however, the dielectric voltage $v_{\text {diel }}$ continues to grow as long as the lamp current remains positive.

When the lamp current falls to zero at the time $t_{\text {off }}$, the bridge turns off (spontaneous turn-off; see Section V), and the lamp is disconnected from the source, as seen in Fig. 2(c); consequently, given the capacitive behavior of the lamp, $v_{\text {lamp }}$ remains constant at its positive peak value.

The next half cycle starts at $T_{\text {bridge }} / 2$, turning on the switch pair $S 3, S 2$. The equivalent circuit in Fig. 2(d) produces a resonant current in the negative direction. In this sequence, the gas voltage is taken from $V_{\mathrm{th}}$ to $-V_{\mathrm{th}}$ to reach again the breakdown condition. When $v_{\text {gas }}$ is equal to $-V_{\mathrm{th}}$, the gas capacitance $C_{\text {gas }}$ is replaced by the inverted voltage source $V_{\text {th }}$ in Fig. 2(e). As done previously for sequence (c), the full bridge is disconnected from the lamp, starting from sequence (f), when the lamp current reaches zero and the lamp voltage reaches its negative peak voltage. This voltage remains constant until

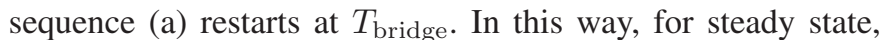
the negative lamp peak voltage and zero lamp current become the initial condition for the equivalent capacitance of the first sequence

$$
v_{\text {lamp }}\left(t_{o}\right)=-\hat{V}_{\text {lamp }} \quad i_{\text {lamp }}\left(t_{o}\right)=0 \mathrm{~A} .
$$

Using the discontinuous current mode (DCM) selected in this work, the lamp operating frequency is defined by only the bridge operation, as presented in Fig. 2 (top right).

The achievement of this DCM is implemented owing to a specific switch, which is presented in Section V. 

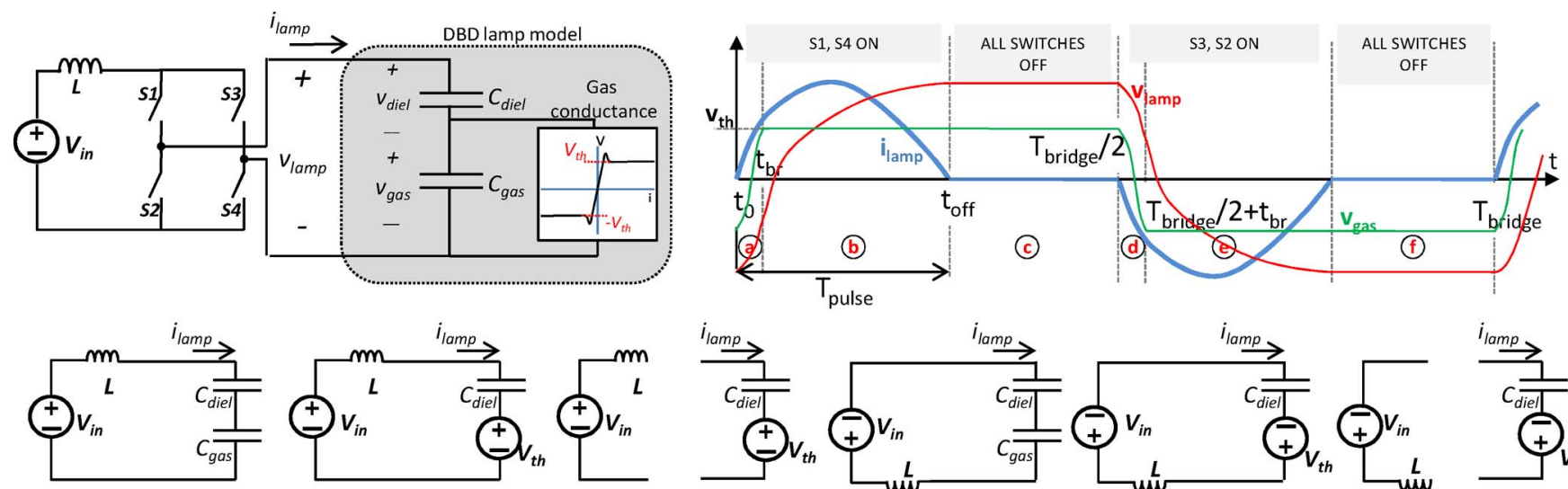

S1, S4 ON

(a)

S1, S4 ON

(b)

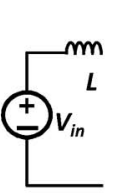

ALL SWITCHES OFF

(c)
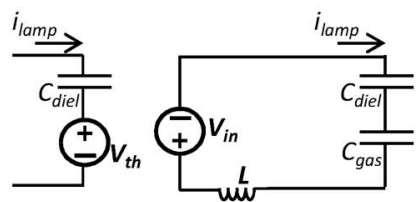

$\mathrm{S3}, \mathrm{S} 2 \mathrm{ON}$

(d)

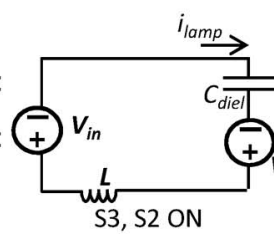

(e)

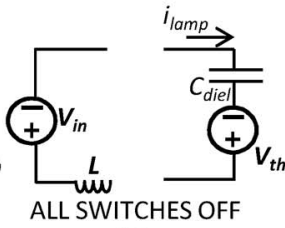

(1)

Fig. 2. (Top left) Proposed SRI and (bottom) its operating sequences. (Top right) Theoretical lamp current and voltage.

\section{Converter Design}

The converter is designed using the state plane analysis [11], [22]. This method allows the determination of the operating conditions for the converter-lamp system, using the equivalent circuits from Fig. 2 (bottom). Although the state plane analysis can be used to find the transient response, only steady state is presented in this paper. Hereafter, the positive current sequences are analyzed; due to symmetry, the study of the negative cycle leads to similar results.

\section{A. State Plane Analysis}

The state plane analysis is used to plot the current-voltage behavior of a resonant circuit. Fig. 2(a) shows the resonant equivalent circuit before gas breakdown occurs.

Normalized units are used, leading to the plot of circular clockwise trajectories [11], [22], describing the current-voltage characteristic for the lamp before ignition, as presented in Fig. 3

$$
\begin{aligned}
& u=\frac{v_{\text {lamp }}}{V_{\text {th }}} \\
& j=\frac{i_{\text {lamp }}}{V_{\mathrm{th}}} \sqrt{\frac{L}{C_{\text {eq }}}}, \quad \text { with } C_{\text {eq }}=\frac{C_{\text {diel }} C_{\text {gas }}}{C_{\text {diel }}+C_{\text {gas }}} .
\end{aligned}
$$

After the gas breaks down, the equivalent resonant circuit changes as shown in Fig. 2(b) with $v_{\text {gas }}$ constant and equal to $V_{\mathrm{th}}$. Therefore, a new state plane is used. This plane draws the normalized current-voltage characteristic for the dielectric capacitor, being the dielectric current equal to the lamp current (Fig. 4).

As the equivalent capacitance has changed from $C_{\mathrm{eq}}$ to $C_{\text {diel }}$, normalization is redefined as follows, using $*$ as notation to remember the lamp ignition:

$$
\begin{aligned}
& u^{*}=\frac{v_{\text {diel }}}{V_{\mathrm{th}}}=\frac{v_{\text {lamp }}-v_{\text {gas }}}{V_{\mathrm{th}}}=\frac{v_{\text {lamp }}}{V_{\mathrm{th}}}-1=u-1 \\
& j^{*}=\frac{i_{\text {lamp }}}{V_{\mathrm{th}}} \sqrt{\frac{L}{C_{\text {diel }}}} .
\end{aligned}
$$

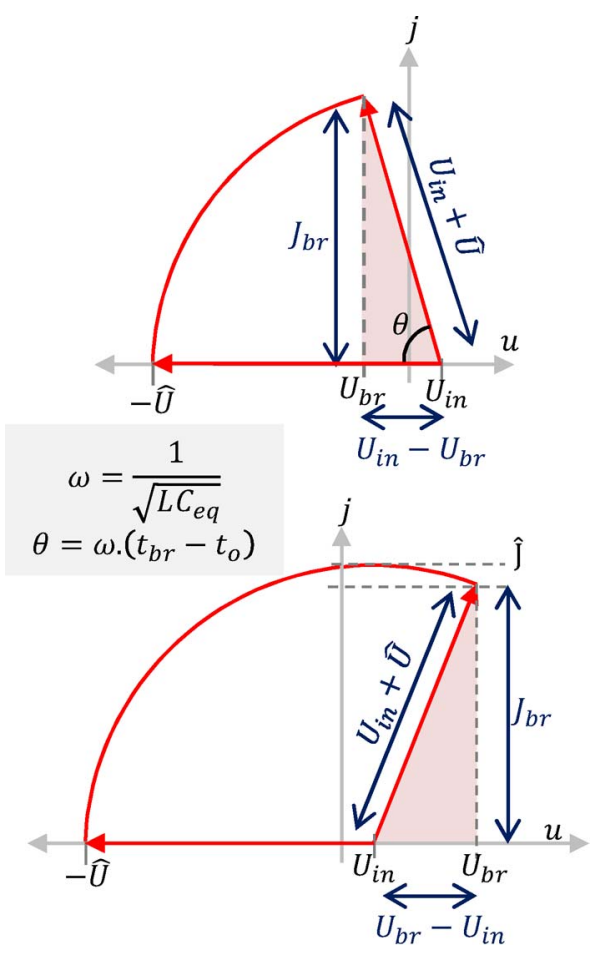

Fig. 3. Two operating conditions before breakdown are plotted in the state plane: When the gas breakdown happens (top) before the peak current and (bottom) after the peak current. Only the positive current half cycle is shown.

\section{B. State Plane: Before Breakdown Trajectory}

As explained in Section III, at the beginning of the positive current cycle, the initial lamp voltage is equal to $-v_{\text {lamp }}$ peak (1), and the initial lamp current is zero.

The normalized lamp current, $j$ in Fig. 3, starts to rise, and the operating point follows a circular path in the plane with the center in $U_{\text {in }}$, as long as this equivalent circuit is valid, i.e., while the gas voltage is inverted from $-V_{\text {th }}$ to $V_{\text {th }}$. In this way, when the gas breakdown occurs, the total voltage change in the gas is $2 V_{\mathrm{th}}$. Accordingly, at the breakdown instant $\left(t_{\mathrm{br}}\right)$, the lamp voltage $U_{\mathrm{br}}$ is calculated using the capacitor voltage equation [23]

$$
U_{\mathrm{br}}=u\left(t_{\mathrm{br}}\right)=-\hat{U}+2\left(1+\frac{C_{\mathrm{gas}}}{C_{\mathrm{diel}}}\right) .
$$




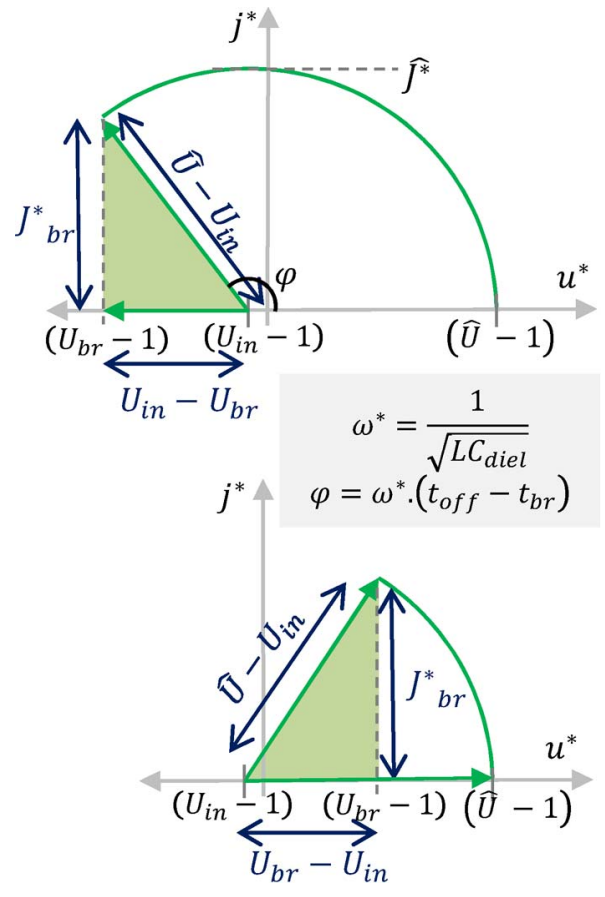

Fig. 4. Two operating conditions are plotted in the state plane after breakdown: When the gas breakdown happens (top) before the peak current and (bottom) after the peak current. Only the positive current cycle is shown.

At the same instant, the lamp current value is defined as the breakdown current $I_{\mathrm{br}}$ and, in the normalized form, as $J_{\mathrm{br}}$. From trigonometric equations for either of the shaded triangles in Fig. 3, we obtain

$$
J_{\mathrm{br}}^{2}=\left(U_{\mathrm{in}}+\hat{U}\right)^{2}-\left(U_{\mathrm{br}}-U_{\mathrm{in}}\right)^{2} .
$$

\section{State Plane: After Breakdown Trajectory}

The initial current for the state plane in Fig. 4 is equal to the breakdown current $I_{\mathrm{br}}$. Given that normalization is different from the previous sequence, (3) and (5) are used to find

$$
J_{\mathrm{br}}^{* 2}=J_{\mathrm{br}}^{2} \frac{C_{\mathrm{eq}}}{C_{\mathrm{diel}}} .
$$

From the equivalent circuit in Fig. 2(b) and (4) at the instant of the gas breakdown, the normalized dielectric voltage $u^{*}\left(t_{\mathrm{br}}\right)$ is equal to

$$
u^{*}\left(t_{\mathrm{br}}\right)=U_{\mathrm{br}}-1
$$

Equation (9) is the dielectric initial voltage for the state plane in Fig. 4. Now, using geometrical relations for either of the shaded triangles in the state plane in Fig. 4, we can write

$$
J_{\mathrm{br}}^{* 2}=\left(\hat{U}-U_{\mathrm{in}}\right)^{2}-\left(U_{\mathrm{br}}-U_{\mathrm{in}}\right)^{2} .
$$

Using (6)-(10) and solving and denormalizing the resulting equation system, we find the lamp peak value in steady state

$$
\hat{V}_{\text {lamp }}=V_{\text {th }}+\frac{V_{\text {th }}^{2} C_{\text {gas }}}{C_{\text {diel }}\left(V_{\mathrm{th}}-V_{\text {in }}\right)} .
$$

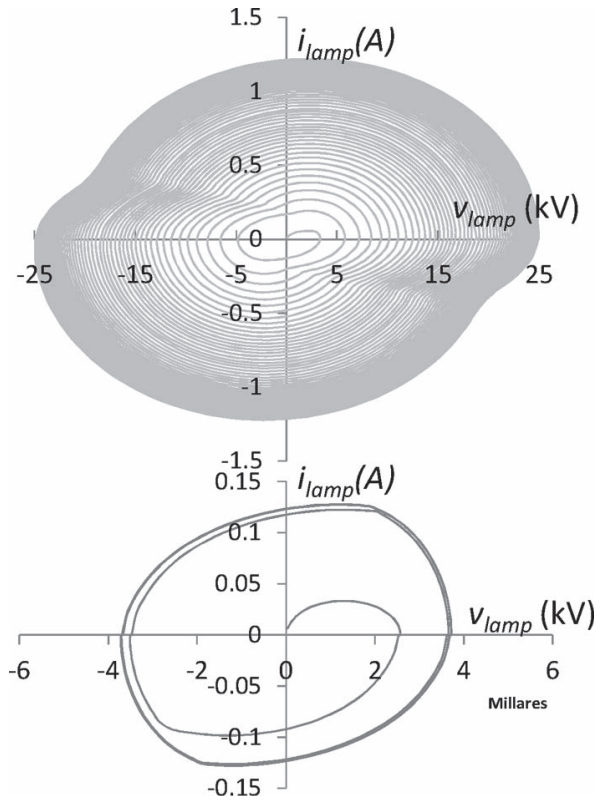

Fig. 5. Transient response from simulation. (Top) Unstable state plane for $V_{\text {in }}>V_{\text {th }}$ and (bottom) stable state plane for $V_{\text {in }}<V_{\mathrm{th}}$.

\section{Operating Conditions}

One should note that the lamp peak voltage depends only on the input voltage and the parameters of the lamp, not on the inductance value. A valid solution for (11) can be found only when condition (12) is fulfilled, operating at the left of the asymptote $V_{\text {th }}$ marked in Fig. 6

$$
V_{\text {in }}<V_{\text {th }} .
$$

Otherwise, unstable operation occurs. The transient state plane trajectory for stable and unstable operating conditions is plotted from simulation in Fig. 5, using the DBD lamp model. The topology of the SRI used in this paper is similar to that presented in the classical resonant step-up voltage converter; the input voltage must be smaller than the output voltage in order to respect the operating principle of this topology [24].

The lamp peak current must be found in two different manners depending on the operating case (Fig. 4, top or bottom). The boundary condition between these two cases is obtained graphically from the state planes in Fig. 3 for a normalized input voltage $\underline{U}_{\text {in }}$ equal to $U_{\text {br }}(6)$ [23].

For the operating case in Fig. 4 (top), the peak lamp current is

$$
\hat{i}_{\text {lamp }}=\left(\hat{v}_{\text {lamp }}-V_{\text {in }}\right) \sqrt{\frac{C_{\text {diel }}}{L}} .
$$

Otherwise,

$$
\hat{i}_{\text {lamp }}=\left(\hat{v}_{\text {lamp }}+V_{\text {in }}\right) \sqrt{\frac{C_{\text {eq }}}{L}} .
$$

The lamp average power is calculated as twice (positive and negative sequences) the power dissipated by the gas conductance 


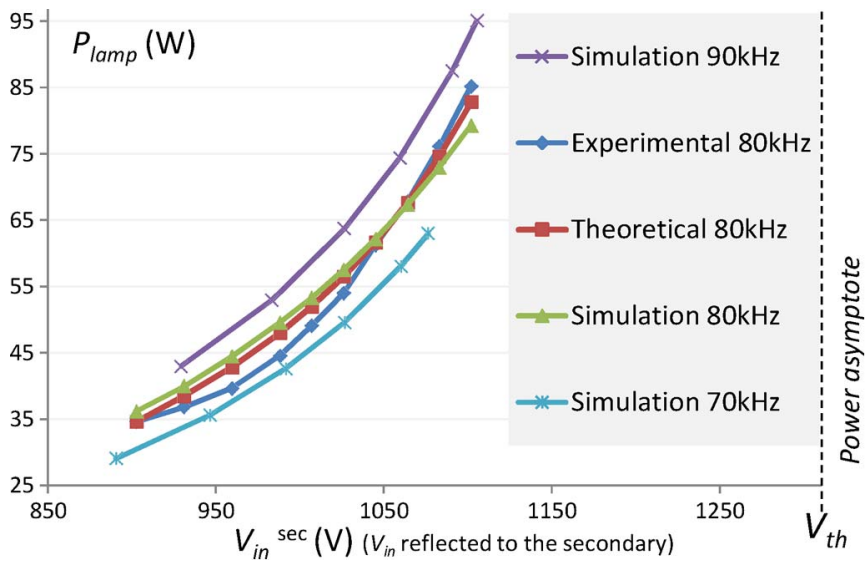

Fig. 6. Power injected into the DBD lamp for different input voltages at constant frequency.

from the time $t_{\mathrm{br}}$ until the discharge dies out at $t_{\mathrm{off}}$ (Fig. 2), obtaining

$$
P_{\text {lamp }}=4 f_{\text {bridge }} V_{\mathrm{th}}^{2} C_{g} \times\left(\frac{V_{\mathrm{th}}}{V_{\mathrm{th}}-V_{\mathrm{in}}}-1\right) .
$$

Expression (15) shows that $P_{\text {lamp }}$ can be adjusted by means of two degrees of freedom: $V_{\text {in }}$ and $f_{\text {bridge. }}$.

For proper operation of the converter, the bridge must be operated at a switching frequency $f_{\text {bridge }}$ which allows the current to fall to zero before the beginning of a new switching sequence. Thus, considering the lamp current waveforms in Fig. 2, condition (16) should be fulfilled

$$
T_{\text {pulse }}<\frac{1}{2 f_{\text {bridge }}} .
$$

With $T_{\text {pulse }}$ computed using the state planes,

$$
\begin{aligned}
T_{\text {pulse }}= & \frac{\theta}{\omega}+\frac{\varphi}{\omega^{*}}=\frac{1}{\omega} \arcsin \left(\frac{I_{\mathrm{br}}}{V_{\mathrm{in}}+\hat{v}_{\text {lamp }}} \sqrt{\frac{L}{C_{\text {eq }}}}\right) \\
& +\frac{1}{\omega^{*}}\left[\pi-\arcsin \left(\frac{I_{\mathrm{br}}}{V_{\mathrm{in}}-\hat{v}_{\text {lamp }}} \sqrt{\frac{L}{C_{\text {diel }}}}\right)\right] .
\end{aligned}
$$

The mathematical relationships exposed in this section have been numerically verified through simulation using the PSIM circuit simulator (Fig. 6) and are used for the converter design and the component selection.

\section{Component Selection and Simulations}

The converter is dimensioned to supply a DBD excimer lamp filled with a $\mathrm{XeCl}$ gas mixture. The equivalent electrical model of this lamp presents a dielectric capacitance $C_{\text {diel }}=95 \mathrm{pF}$, a gas capacitance $C_{\mathrm{gas}}=28.5 \mathrm{pF}$, and a breakdown voltage $V_{\mathrm{th}}=1.31 \mathrm{kV}$ [25]. This lamp has been designed to accept approximately $90 \mathrm{~W}$ of electrical power.
TABLE I

Theoretical Operating Point

\begin{tabular}{|c|c|c|c|c|c|}
\hline$P_{\text {lamp }}$ & $f_{\text {lamp }}$ & $V_{\text {in }}$ & $\hat{v}_{\text {lamp }}$ & $\hat{I}_{\text {lamp }}$ & $I_{b r}$ \\
\hline $90 \mathrm{~W}$ & $80 \mathrm{kHz}$ & $1116 \mathrm{~V}$ & $3.96 \mathrm{kV}$ & $182 \mathrm{~mA}$ & $147 \mathrm{~mA}$ \\
\hline
\end{tabular}

\section{A. Operating Point}

According to the experimental results presented in [7] and [12] and studies in [2], [26], and [27], an excimer lamp with similar characteristics to the one that we intend to supply is typically operated at current frequencies in the range of tens of kilohertz. In particular, from the results in [10], the lamp performance is severely affected by operating frequencies above $100 \mathrm{kHz}$; consequently, we chose $f_{\text {lamp }}=80 \mathrm{kHz}$ for the converter validation. At this frequency, the theoretical voltages and currents for a maximum $P_{\text {lamp }}=90 \mathrm{~W}$ are presented in Table I.

In order to validate the converter behavior, the converter control is implemented in open loop, adjusting $P_{\text {lamp }}$ with $V_{\text {in }}$ remaining in the stability region illustrated in Fig. 5 (bottom).

\section{B. Switches}

For this range of operating frequencies, high switching speed offered by the MOSFET technology is necessary. Studying the current-voltage characteristic for each switch, unidirectional current switches capable of blocking bipolar voltage should be used in the bridge. This switch characteristic corresponds to a thyristor-like device [28] and is implemented by connecting a diode (GB07SHT12) in series with a MOSFET (P8NK100Z) (Fig. 7).

\section{Step-Up Transformer}

The voltage values at the chosen operating point (Table I) lead to the use of a step-up transformer connecting the DBD lamp to the inverter. The implemented step-up transformer has been designed with a transformation ratio of ten to reduce the peak voltage of the bridge switches to approximately $400 \mathrm{~V}$.

Using the theoretical lamp peak current in Table I and ten as the transformation ratio, the transformer wires are selected: 81 strands of 38 AWG litz wire for the primary and 33 AWG single copper wire for the secondary.

The construction of this transformer is a challenge, since its parasitic capacitance ( $C_{s}$ seen in the secondary) should be much smaller than the lamp equivalent capacitance, in order to avoid any difference between the current injected by the converter and the transformed current seen from the lamp. At the same time, magnetizing inductance should be maximized to conserve the operating principle presented in this paper.

To satisfy these two opposite criteria, in accordance with [29] and [30], the best solution has been found by using onelayer winding coil. The values obtained for the experimental transformer are summarized in the circuit in Fig. 7. 


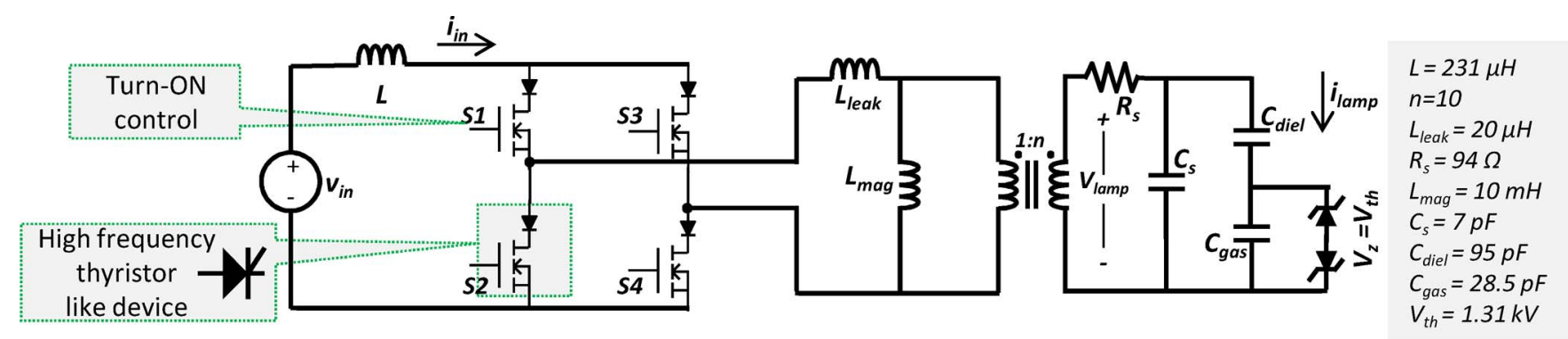

Fig. 7. Converter circuit and DBD electrical model used for simulation.

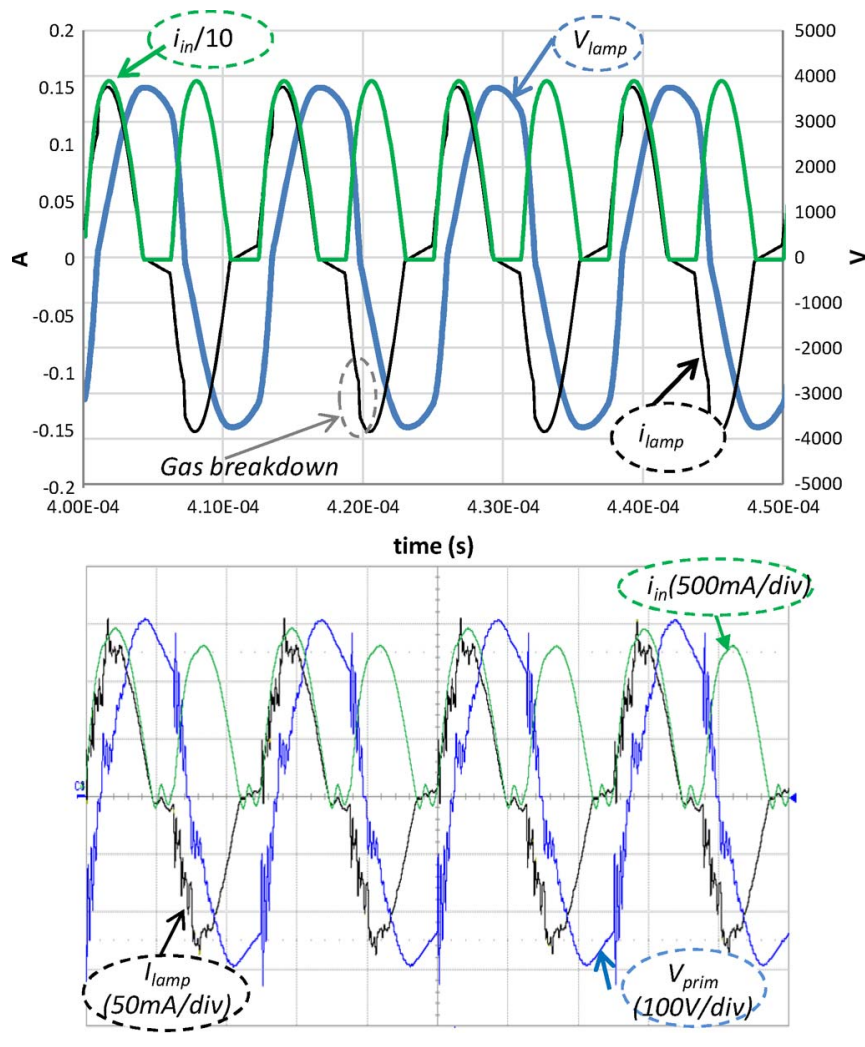

Fig. 8. Waveform comparison (top) from simulation and (bottom) from the experimental validation. $f_{\text {lamp }}=80 \mathrm{kHz}$ and $V_{\text {in }}=115 \mathrm{~V}$.

\section{Inductance Value}

The value of $L$ (Table I) is calculated taking into account the condition (16) and the component current ratings (13). An inductance value of $23 \mathrm{mH}$ seen on the secondary is calculated based on (17) to obtain a duty cycle of approximately $70 \%$ at $f_{\text {lamp }}=80 \mathrm{kHz}$. This duty cycle provides enough dead time for the switch turn-off and for the increase of the switching frequency if necessary. Given a transformation ratio of ten, an inductance $L=231 \mu \mathrm{H}$ is used in the primary side.

\section{E. Simulations}

The converter, including the transformer parasitic elements (Fig. 7), has been simulated using PSIM. The waveforms obtained from this simulation are presented in Fig. 8 (top). The step observed in the lamp current waveform $i_{\text {lamp }}$ (marked as "Gas breakdown") is a result of the gas breakdown that changes the current divider between the lamp equivalent capacitance and the transformer parasitic capacitance [30]. The $i_{\text {lamp }}$ is not zero during the dead time due to the effect of the magnetizing inductance.

The output power $P_{\text {lamp }}$ obtained in simulation is presented in Fig. 6 for different values of $f_{\text {lamp. }}$ Because of the transformer frequency response, the equivalent transformer gain changes with the frequency operation; consequently, the equivalent input voltage is reflected to the secondary using the transformer gain measured experimentally: 9.3, 9.5, and 9.7 for 70, 80, and $90 \mathrm{kHz}$, respectively.

\section{EXPERIMENTAL RESULTS}

The experimental validation of the proposed converter has been achieved by measuring the electrical signals for the system with a high-speed current probe (LeCroy AP015) and a highvoltage differential probe (Agilent N2891A). The lamp voltage is measured in the primary side of the transformer $\left(v_{\text {prim }}\right)$ to reduce the impact of the voltage probe input impedance (approximately $3.5 \mathrm{pF}$ ) in the resonant circuit.

\section{A. Electrical Waveforms}

In Fig. 8 (bottom), the inductance current $i_{\text {in }}$ is shown. The lamp voltage $v_{\text {lamp }}$, measured at the primary side of the transformer, does not remain constant when the current is zero because the transformer magnetizing inductance is not as big as desired. The transformer parasitic elements also affect the power transfer, as shown in Fig. 6: Simulation results taking into account these parasites are very near to the experimental measurements allowing fine adjust of the design, while theoretical ones are less precise.

\section{B. Performance}

The benefits of the SRI are validated experimentally by measuring and comparing its performance with the squarewaveform current supply previously proposed in [10].

1) Efficiency: The measurement of the converter efficiency, in terms of electrical power supplied to the lamp, is obtained as follows: The $v_{\text {prim }}$ and $i_{\text {lamp }}$ output signals are multiplied in the oscilloscope, computing the lamp instantaneous power. Then, this power signal is averaged (averaging time of $1 \mathrm{~ms}$ ) and multiplied by the transformation ratio, obtaining $P_{\text {lamp. In }}$ a similar manner, the power supplied by the constant voltage source $P_{\text {in }}$ is found, computing the converter efficiency as $P_{\text {lamp }} / P_{\text {in }}$. 


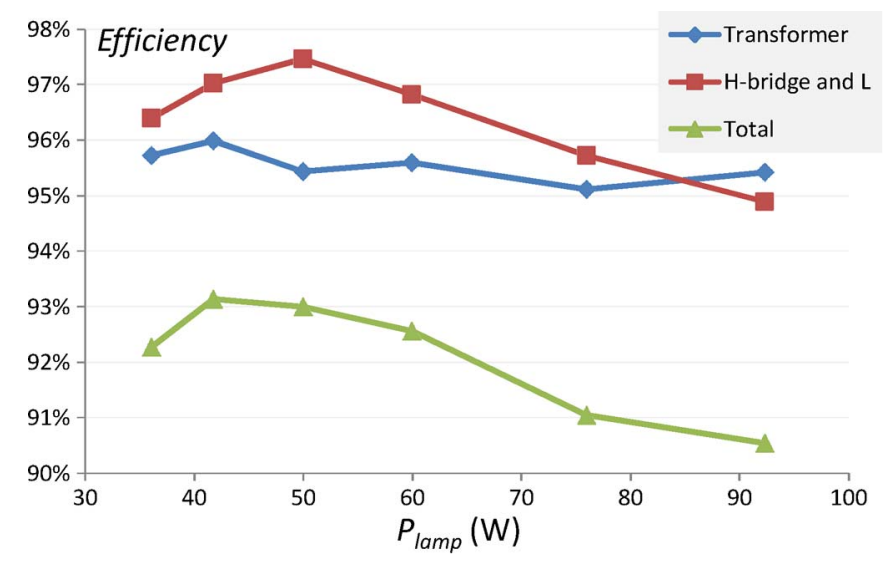

Fig. 9. Measured efficiencies of the SRI for different values of output power at $f_{\text {lamp }}=80 \mathrm{kHz}$.

The measurement of $P_{\text {lamp }}$ obtained for different values of $V_{\text {in }}$ at $f_{\text {lamp }}=80 \mathrm{kHz}$ is presented in Fig. 6, and the corresponding converter efficiencies are shown in Fig. 9. It is found that the transformer is responsible for most of the converter losses.

In comparison, for the square-waveform current supply proposed in [10] at the particular operating point of $P_{\text {lamp }}=90 \mathrm{~W}$, $f_{\text {lamp }}=80 \mathrm{kHz}$, a duty cycle of $53 \%$, and a current intensity of $125 \mathrm{~mA}$, the converter efficiency obtained is $57 \%$, against $91 \%$ for the SRI.

2) Stability: For an input voltage slightly higher than $117 \mathrm{~V}$, which corresponds to approximately $1170 \mathrm{~V}$ in the secondary, the proximity to the asymptote $\left(V_{\mathrm{th}}=1.31 \mathrm{kV}\right.$ in Fig. 6) produces an erratic behavior of the system, with intermittent variations of up to $50 \mathrm{~W}$ in $P_{\text {lamp }}$ for a constant value of $V_{\text {in }}$.

As $V_{\text {in }}$ approaches to the asymptote, the system is more susceptible to small perturbations caused by the main voltage source or by the dynamic behavior of the lamp, which is not included in the lamp simplified model used for this design.

3) EMI: The SRI is an advantageous supply in terms of EMI when compared with a hard-switching topology. This benefit is evaluated by performing a fast Fourier transform (FFT) of the lamp current for both topologies under similar operating conditions of $f_{\text {lamp }}$ and output power (Fig. 10).

4) UV Radiation: For the $\mathrm{XeCl}$ excimer lamp used as load, the typical radiation wavelength is $308 \mathrm{~nm}$; the UV radiation power is measured with the optometer OPTIK P-9710 using the UV detector SN5816, installed at $12 \mathrm{~mm}$ of the lamp surface. The UV power obtained using the SRI at $P_{\text {lamp }}=90 \mathrm{~W}$ and $f_{\text {lamp }}=80 \mathrm{kHz}$ is $17.7 \mathrm{~mW} / \mathrm{cm}^{2}$. For the same lamp power, frequency, and pulse duration, the UV radiation obtained with the square-waveform current is $20 \mathrm{~mW} / \mathrm{cm}^{2}$. This result reveals a decrease of around $10 \%$ in the UV power due to the current form factor.

The UV waveform is acquired with a Thorlabs PDA-25K photodetector, installed at $25 \mathrm{~mm}$ of the lamp surface. As already mentioned in [9], as can be seen in Fig. 11, the waveform of the UV radiation is similar to the $i_{\text {lamp }}$ lamp current waveform (absolute value).

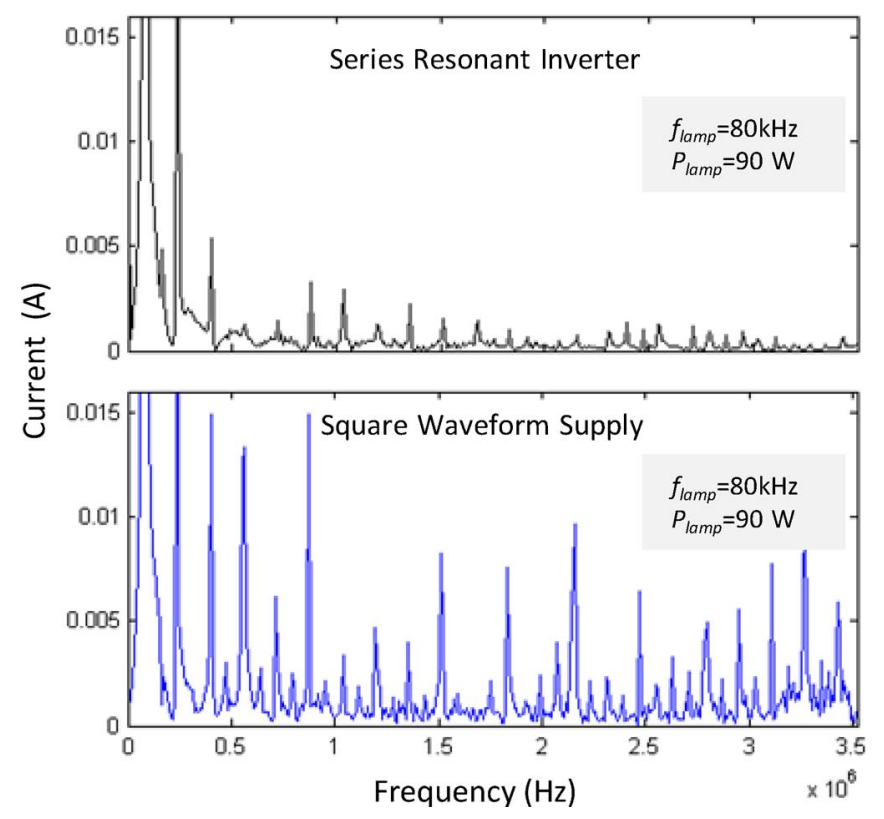

Fig. 10. FFT of the lamp current for SRI and square-waveform current-source topologies.

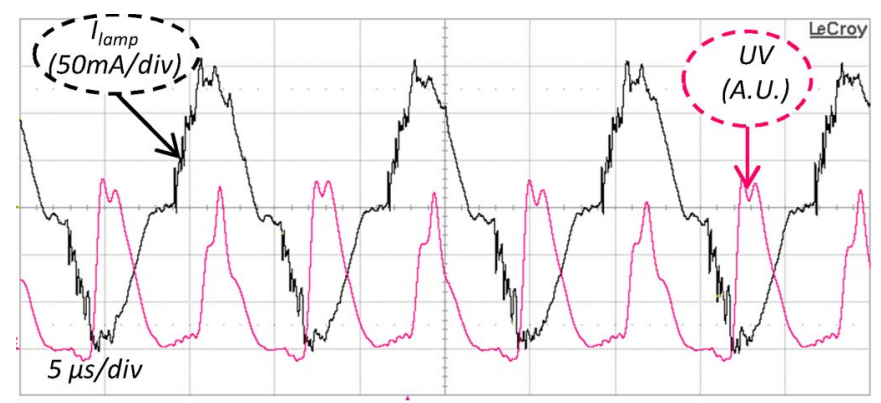

Fig. 11. UV waveform and excilamp current for the SRI.

\section{CONCLUSION}

The use of the SRI topology, operating in DCM, has been proved to be a good option to supply a DBD excimer lamp. With the operating mode selected in this work, the lamp power is imposed with two degrees of freedom, and ZCS is achieved, reducing switching losses and EMI. The use of the lamp electrical model, in conjunction with the state plane analysis, gives an insight into the process and allows the calculation of the electrical values, including the lamp power, as a function of the input voltage, the inverter frequency, the components, and the parameters of the lamp. Analytical study, simulation, and experimental results are in accordance, validating the SRI as an efficient topology for the supplying of DBD excimer lamps. Satisfactory efficiency results of up to $93 \%$ have been obtained for the converter supplying a DBD UV excimer lamp.

\section{ACKNOWLEDGMENT}

Part of this study is in the framework of French-Colombian cooperation, with the support of the ECOS program (ECOS Nord, Colciencias-ICETEX). 


\section{REFERENCES}

[1] U. Kogelschatz, "Dielectric-barrier discharges: Their history, discharge physics, and industrial applications," Plasma Chem. Plasma Process., vol. 23, no. 1, pp. 26-31, Mar. 2003.

[2] M. I. Lomaev, V. S. Skakun, A. Sosnin, V. F. Tarasenko, D. V. Shitts, and M. V. Erofeev, "Excilamps: Efficient sources of spontaneous UV and VUV radiation," Physics-Uspekhi, vol. 46, no. 2, pp. 193-209, 2003.

[3] E. Panousis, N. Merbahi, F. Clement, M. Yousfi, J.-F. Loiseau, O. Eichwald, and B. Held, "Analysis of dielectric barrier discharges under unipolar and bipolar pulsed excitation," IEEE Trans. Dielect. Elect. Insul., vol. 16, no. 3, pp. 734-741, Jun. 2009.

[4] M. Meisser, R. Kling, and W. Heering, "Universal resonant topology for high frequency pulsed operation of dielectric barrier discharge light sources," in Proc. 26th Annual IEEE APEC, 2011, pp. 1180-1187.

[5] H. Fujita and H. Akagi, "Control and performance of a pulse-densitymodulated series-resonant inverter for corona discharge processes," IEEE Trans. Ind. Appl., vol. 35, no. 3, pp. 621-627, May/Jun. 1999.

[6] S. Kalisiak, M. Holub, and T. Jakubowski, "Resonant inverter with output voltage pulse-phase-shift control for DBD plasma reactor supply," in Proc. 13th EPE, 2009, pp. 1-9.

[7] R. Diez, H. Piquet, M. Cousineau, and S. Bhosle, "Current-mode power converter for radiation control in DBD excimer lamps," IEEE Trans. Ind. Electron., vol. 59, no. 4, pp. 1912-1919, Apr. 2012.

[8] H. Piquet, S. Bhosle, R. Diez, and M. Erofeev, "Pulsed current-mode supply of dielectric barrier discharge excilamps for the control of the radiated ultraviolet power," IEEE Trans. Plasma Sci., vol. 38, no. 10, pp. 2531-2538, Oct. 2010.

[9] R. Diez, H. Piquet, and S. Bhosle, "Control of the UV emission of an excimer lamp by means of a current-mode power supply," in Proc. 35th Annu. IEEE IECON, 2009, pp. 3500-3505.

[10] D. Flórez, R. Díez, K. Hay, and H. Piquet, "DBD excimer lamp power supply with fully controlled operating conditions," in Proc. IEEE OPTIM Conf., 2012, pp. 1346-1352.

[11] Y. Chéron, Soft Commutation. London, U. K.: Chapman \& Hall, 1992.

[12] A. El-Deib, F. Dawson, G. van Eerden, S. Bhosle, G. Zissis, and T. D. Le, "Analysis and experimental validation of a new current-controlled driver for a dielectric barrier discharge lamp," IEEE Trans. Ind. Appl., vol. 47, no. 4, pp. 1971-1982, Jul./Aug. 2011.

[13] J. Alonso, J. Garcia, A. Calleja, J. Ribas, and J. Cardesin, "Analysis, design, and experimentation of a high-voltage power supply for ozone generation based on current-fed parallel-resonant push-pull inverter," IEEE Trans. Ind. Appl., vol. 41, no. 5, pp. 1364-1372, Sep./Oct. 2005.

[14] C. Branas, F. J. Azcondo, and S. Bracho, "Design of $\mathrm{LC}_{\mathrm{p}} \mathrm{C}_{\mathrm{s}}$ resonant inverters as a power source for HID lamp ballast applications," IEEE Trans. Ind. Appl., vol. 41, no. 6, pp. 1584-1593, Nov./Dec. 2005.

[15] R. Casanueva, F. J. Azcondo, and S. Bracho, "Series-parallel resonant converter for an EDM power supply," J. Mater. Process. Technol., vol. 149, no. 1-3, pp. 172-177, Jun. 2004.

[16] P. C. Theron and J. A. Ferreira, "The zero voltage switching partial series resonant converter," IEEE Trans. Ind. Appl., vol. 31, no. 4, pp. 879-886, Jul./Aug. 1995.

[17] H. Fujita and H. Akagi, "A 2-MHz 2-kW voltage-source inverter for lowtemperature plasma generators: Implementation of fast switching with a third-order resonant circuit," IEEE Trans. Ind. Appl., vol. 35, no. 1, pp. 21-27, Jan./Feb. 1999

[18] A. K. S. Bhat and S. B. Dewan, "A generalized approach for the steadystate analysis of resonant inverters," IEEE Trans. Ind. Appl., vol. 25, no. 2, pp. 326-338, Mar./Apr. 1989.

[19] A. Oda, Y. Sakai, H. Akashi, and H. Sugawara, "One-dimensional modelling of low-frequency and high-pressure Xe barrier discharges for the design of excimer lamps," J. Phys. D, Appl. Phys., vol. 32, no. 21, pp. 2726-2736, Nov. 1999.

[20] S. Bhosle, S. Zissis, J. Damelincourt, A. Capdevila, K. Gupta, F. Dawson, and V. Tarasenko, "Implementation of an efficiency indicator in an electrical modeling of a dielectric barrier discharge Lamp," in Conf. Rec. 41st IEEE IAS Annu. Meeting, 2006, pp. 1784-1790.

[21] R. Díez, J.-P. Salanne, H. Piquet, S. Bhosle, and G. Zissis, "Predictive model of a DBD lamp for power supply design and method for the automatic identification of its parameters," Eur. Phys. J. Appl. Phys., vol. 37, no. 3, pp. 307-313, Mar. 2007.

[22] R. Oruganti and F. C. Lee, "Resonant power processors, Part I-State plane analysis," IEEE Trans. Ind. Appl., vol. IA-21, no. 6, pp. 1453-1460, Nov. 1985

[23] D. Florez, R. Diez, and H. Piquet, "Series-resonant inverter in DCM mode for the supply of a DBD excimer UV lamp," in Conf. Rec. IEEE IAS Annu. Meeting, Oct. 7-11, 2012, pp. 1-8.
[24] Erickson, W. Robert, and D. Maksimovic, Fundamentals of Power Electronics. New York, NY, USA: Springer-Verlag, 2001, p. 778.

[25] A. M. Lopez, H. Piquet, D. Patiño, R. Diez, and X. Bonnin, "Parameters identification and gas behavior characterization of DBD systems," IEEE Trans. Plasma Sci., vol. 41, no. 8, pp. 2335-2342, Aug. 2013.

[26] R. Hippler, Low Temperature Plasmas: Fundamentals, Technologies and Techniques. Hoboken, N. J., USA: Wiley-VCH, 2008.

[27] E. A. Sosnin, T. Oppenlä, and V. F. Tarasenko, "Applications of capacitive and barrier discharge excilamps in photoscience," J. Photochem. Photobiol. C, Photochem. Rev., vol. 7, no. 4, pp. 145-163, Dec. 2006.

[28] M. Cousineau, R. Diez, H. Piquet, and O. Durrieu, "Synthesized highfrequency thyristor for dielectric barrier discharge excimer lamps," IEEE Trans. Ind. Electron., vol. 59, no. 4, pp. 1920-1928, Apr. 2012.

[29] J. Biela and J. W. Kolar, "Using transformer parasitics for resonant converters-A review of the calculation of the stray capacitance of transformers," IEEE Trans. Ind. Appl., vol. 44, no. 1, pp. 223-233, Jan./ Feb. 2008.

[30] X. Bonnin, H. Piquet, N. Naudé, C. Bouzidi, N. Gherardi, and J. M. Blaquière, "Design of a current converter to maximize the power into homogeneous dielectric barrier discharge (DBD) devices," Eur. Phys. J., Appl. Phys., vol. 64, 2013, DOI: 10.1051/epjap/2013130080.

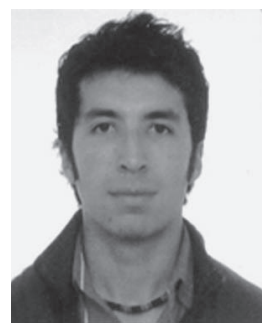

David Florez (M'12) received the B.S. degree in electronics engineering from the Pontificia Universidad Javeriana, Bogotá, Columbia, in 2005 and the M.S. degree in the domain of critical systems and networks from the Université Paul Sabatier, Toulouse, France, in 2006. He is currently working toward the Ph.D. degree at the Pontificia Universidad Javeriana and the Institut National Polytechnique de Toulouse, Toulouse.

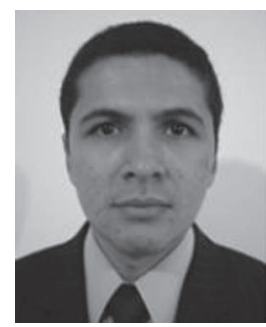

Rafael Diez (M'10) received the B.S. degree in electronics engineering from the Pontificia Universidad Javeriana, Bogotá, Colombia, in 2001 and the M.S. and Ph.D. degrees from the Université de Toulouse, Toulouse, France, in 2005 and 2008, respectively.

$\mathrm{He}$ is currently an Assistant Professor with the Department of Electronics Engineering, Pontificia Universidad Javeriana. He is mainly interested in the development of power converters for electric discharges.

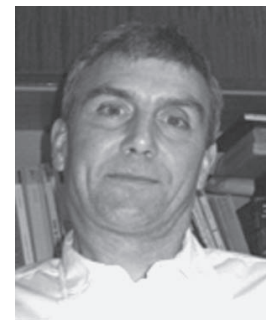

Hubert Piquet was born in Arras, France, in 1960. He received the B.S. degree in applied physics from the Ecole Normale Supérieure de Cachan, Cachan, France, in 1984 and the Ph.D. degree in electrical engineering from the Institut National Polytechnique de Toulouse, Toulouse, France, in 1990.

$\mathrm{He}$ is currently a Full Professor with the Ecole Nationale Superieure d'Electrotechnique, d'Electronique, d'Informatique, d'Hydraulique et des Télécommunications, Institut National Polytechnique de Toulouse, where he teaches courses on power electronics and systemic approach in electrical engineering. His research activity takes place in the Laboratoire Plasma et Conversion d'Energie (Unité Mixte de Recherche 5213), Centre National de la Recherche Scientifique-Institut National Polytechnique de Toulouse-Université Paul Sabatier, Université de Toulouse, Toulouse. His main research interests include quality and stability in embedded networks as well as power supplies for plasma applications 